\title{
PReS-FINAL-2208: Sacroilitis with propionibacterium acnes in a child
}

\author{
C Galeottiं, I Koné-Paut \\ From 20th Pediatric Rheumatology European Society (PReS) Congress \\ Ljubljana, Slovenia. 25-29 September 2013
}

\begin{abstract}
Introduction
The syndrome of synovitis, acne, pustulosis, hyperostosis and osteitis (SAPHO) is a rare autoinflammatory syndrome, affecting essentially the adults. Osteitis with Propionibacterium Acnes (P.Acnes) reported in the literature is generally connected to the presence of a foreign body or with the SAPHO syndrome. Chronic recurrent multifocal osteomyelitis (CRMO) is a disease related to the SAPHO syndrome, affecting the children. There is essentially an isolated bone inflammation.
\end{abstract}

\section{Objectives}

We report the case of a 16 year-old girl, affected with a sacroiliitis for 5 years.

\section{Methods}

The patient had a bone biopsy highlighted an infection to P.Acnes.

\section{Results}

This girl presented chronic pain at left sacroiliac for 5 years, with regional amyotrophy and a limping. The scanner showed a left condensed sacral fine, with multiple geodes. The right sacroiliac was normal. In the hypothesis of an infection of atypical germs, a left sacroiliac biopsy was realized. There was no inflammatory infiltrate, in particular no epithelioid granuloma. But P.Acnes has been recovered from bone biopsy samples. The whole body MRI showed an aspect of sclerosis of the spongy bone of the sacred hillside of the left sacroiliac, and the absence of lesion of the other side and the whole body. The patient was treated with NSAID then clindamycin in the hypothesis of a SAPHO syndrome. We observed a decrease of pain and the stability of the lesions after 4-months treatment with

\footnotetext{
Pediatrics and pediatric rheumatology, BICÊTRE HOSPITAL, Le KremlinBicêtre
} Cédex, France

\section{Conclusion}

The association sacroiliitis and P.Acnes thus directs us to a SAPHO syndrome, exceptionnaly reported in children; furthermore, our patient has an isolated osteitis lesion, without cutaneous lesion. Assman et al treated in 200930 patients having a SAPHO syndrome by azithromycin, doxycycline or clindamycin. He has found P.Acnes by 14 patients who had a bone biopsy. They received a 16-week treatment with antibiotics. For the period of application, the antibiotic therapy seems to have controlled the disease. After antibiotic discontinuation, however, disease relapse was observed. Our patient could have a CRMO, which is related to the SAPHO. There is no case of CRMO associated with P. Acnes reported in the literature. On the other hand, Schilling et al treated 13 teenagers having a CRMO by azithromycin, without infectious documentation. Seven children had a very fast decrease of the pain and an improvement of mobility. Other diagnostic hypothesis at these patient would be a spondylarthropathy, but the fact that she has an unilateral sacroiliitis with P.Acnes and that she has no HLA B27 antigen are not in favour. The bone biopsy finding P.Acnes guided us to a cause of ostiitis and allowed us to propose a treatment which seems to be suspensive.

\section{Disclosure of interest}

None declared.

Published: 5 December 2013

doi:10.1186/1546-0096-11-S2-P198

Cite this article as: Galeotti and Koné-Paut: PReS-FINAL-2208: Sacroilitis with propionibacterium acnes in a child. Pediatric Rheumatology 201311 (Suppl 2):P198. 